\title{
Test Anxiety among School-Going Children and Adolescents, Factors Affecting and Impact on Quality of Life: A Multicenter Study: Authors' Reply
}

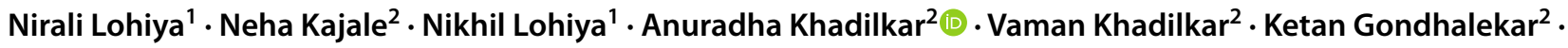 \\ Sharad Agarkhedkar ${ }^{1}$
}

Received: 8 June 2021 / Accepted: 18 June 2021 / Published online: 8 July 2021

(c) Dr. K C Chaudhuri Foundation 2021

To the Editor: We thank Panda et al. for their comments [1]. We agree that curriculum and examination pattern are very different between private and public schools. All our rural schools were public and urban schools were private [2]. Thus, rural/urban independent variable in our regression was a stand-in for public/private schools.

Quality of life (QOL) can be a cause as well as consequence of anxiety [3]. Our study was designed to assess test anxiety (TA) in school-going children, thus we used QOL as an independent and TA as a dependent variable.

We agree that there are several confounding variables impacting TA; however, ours was a school-based multicentric study and using instruments requiring time to administer such as the Child Behavioral Check List (CBCL) and Learning Disability Screening Questionnaire (LDSQ), were beyond the scope of our study. We screened school records (as teachers play an essential part in reporting for tools like CBCL and LDSQ) [4] for known comorbidities like attention deficit disorder and learning disabilities in children, but no formal testing was performed.

We agree adolescents appearing for board examinations may possibly suffer from higher test anxiety. However, we wanted to look at a broader picture of correlating anxiety with age, thus we worked with 9-18 y olds. We also believe that the TA may be attributed to cognitive appraisal [5] of the child rather than merely the board examinations. Further, it is true that most students feel more anxious as the exam

Anuradha Khadilkar

anuradhavkhadilkar@gmail.com

1 Department of Pediatrics, Dr D Y Patil Medical College, Hospital and Research Center, Pune 411001, Maharashtra, India

2 Department of Growth and Pediatric Endocrinology, Hirabai Cowasji Jehangir Medical Research Institute, Pune, Maharashtra, India approaches, a question on the same is included in the TA inventory and is part of our dependent variable.

Steinmayr et al., describe impact of grade point average on TA [6]. We too made an attempt to obtain scores of students to study association between TA and academic performance. Since the exam patterns were very different, we did not explore the association.

\section{Declarations}

Conflict of Interest None.

\section{References}

1. Panda PK, Sharawat IK. Test anxiety among school-going children and adolescents, factors affecting and impact on quality of life: a multicenter study: correspondence. Indian J Pediatr. 2021. https:// doi.org/10.1007/s12098-021-03866-7.

2. Lohiya N, Kajale N, Khadilkar A, et al. Test anxiety among school-going children and adolescents, factors affecting and impact on quality of life: a multicenter study. Indian J Pediatr. 2021. https://doi.org/10.1007/s12098-021-03676-x.

3. Quilty LC, Van Ameringen M, Mancini C, Oakman J, Farvolden P. Quality of life and the anxiety disorders. J Anxiety Disord. 2003;17:405-26.

4. Fazel M, Hoagwood K, Stephan S, Ford T. Mental health interventions in schools in high-income countries. Lancet Psychiatry. 2014;1:377-87.

5. Folkman S, Lazarus RS, Dunkel-Schetter C, DeLongis A, Gruen RJ. Dynamics of a stressful encounter: cognitive appraisal, coping, and encounter outcomes. J Pers Soc Psychol. 1986;50:992-1003.

6. Steinmayr R, Crede J, McElvany N, Wirthwein L. Subjective Well-Being, test anxiety, academic achievement: testing for reciprocal effects. Front Psychol. 2016;6:1994.

Publisher's Note Springer Nature remains neutral with regard to jurisdictional claims in published maps and institutional affiliations. 